\title{
LETRAMENTOS E EDUCAÇÃO: NOVAS PERSPECTIVAS DE ANÁLISE
}

\section{LITERACY AND EDUCATION: NEW PERSPECTIVES OF ANALYSIS}

\section{LETRAMENTOS Y EDUCACIÓN: NUEVAS PERSPECTIVAS DE ANÁLISIS}

STREET, Brian V. Letramentos sociais: abordagens críticas do letramento no desenvolvimento, na etnografia e na educação. Tradução de Marcos Bagno. São Paulo: Parábola Editorial, 2014. 240p.

Maria Carolina da Silva Caldeira ${ }^{\mathrm{I}}$

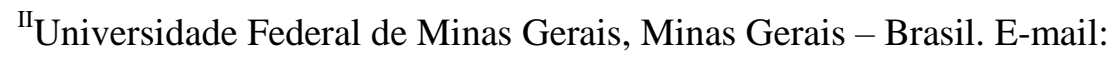

mariacarolinasilva@hotmail.com

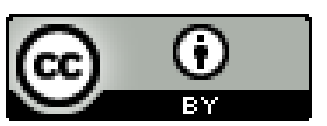

Educação: Teoria e Prática, Rio Claro, SP, Brasil - eISSN: 1981-8106

Está licenciada sob Licença Creative Common

Há cerca de vinte anos o termo letramento começou a ser divulgado no Brasil. Cunhado nos países de língua inglesa para referir-se àqueles/as que, apesar de alfabetizados/as, não faziam uso social da cultura escrita em suas práticas cotidianas, o termo 
foi amplamente incorporado nas pesquisas educacionais, fazendo com que novos temas e perspectivas fossem incluídos por pesquisadores/as brasileiros/as. Apesar disso, como afirma Soares $(2010$, p. 55) "estamos sempre discutindo o que é letramento... e acredito que ainda não chegamos a um consenso". Tendo em vista esse quadro conceitual de ampliação e incertezas, o livro "Letramentos sociais", do professor do King's College London, Brian Street, pode auxiliar em uma complexificação do conceito de letramento, bem como possibilitar ferramentas teórico-analíticas que permitam a ampliação das pesquisas já realizadas no Brasil acerca desse tema.

O livro constitui-se de uma série de artigos e ensaios publicados por Street ao longo dos anos 1990. Embora lançados em diferentes momentos e para atender a objetivos diversos, o livro apresenta uma unidade temática, qual seja, a defesa de que os letramentos são marcados pelas relações de poder que configuram determinada sociedade e a noção de que, na maioria dos casos, opera-se nas pesquisas e políticas com uma noção autônoma de letramento. Tendo em vista esse fio condutor, a distinção entre o que o autor nomeia como "letramento autônomo" e "letramento ideológico" permeia as cinco sessões do livro.

A primeira dessas sessões - intitulada "Letramento, política e mudança social" inicia-se com um artigo no qual o autor analisa os vários estereótipos divulgados no "Ano Internacional da Alfabetização" (1990). Street defende o argumento de que, nessa campanha, divulgava-se a ideia de que o letramento, por si só, seria capaz de promover mudança social e tirar os/as analfabetos/as de um suposto atraso cultural, o que caracteriza a noção de letramento autônomo. Em oposição a esse modelo autônomo de letramento, que deposita a crença na mudança social na aquisição de habilidades cognitivas relativas à cultura escrita, é proposto o modelo ideológico. Com base em pesquisas etnográficas, mostra-se como os diferentes grupos alvos dessas campanhas de alfabetização, longe de serem passivos ou atrasados, "têm seus próprios letramentos, suas próprias habilidades e convenções de linguagem e suas próprias maneiras de apreender os novos letramentos fornecidos pelas agências, pelos missionários e pelos governos locais" (p. 37). Defende-se, então, que o letramento em si mesmo não promove mobilidade social, avanço cognitivo ou progresso, pois "práticas letradas são específicas ao contexto político e ideológico e suas consequências variam conforme a situação" (p. 41). Dessa forma, pode-se inferir que uma das razões para o fracasso de tais campanhas refere-se ao conceito de letramento que as subjaz, pois nesse processo desconsideram-se os múltiplos letramentos locais. 
Em oposição a esse modelo de políticas públicas, o autor propõe no segundo capítulo da primeira sessão que os programas de letramento devem estar assentados nas culturas locais. Deve-se também considerar os impactos sociais que a introdução da escrita vai ter em dada cultura, já que não se trata apenas da aprendizagem de certas técnicas, mas em mudanças diversas, que podem, inclusive, impactar nos aspectos ideológicos, culturais e epistemológicos de determinado grupo. Para exemplificar como isso se dá, Street mostra as alterações culturais provocadas na Inglaterra Medieval quando os normandos introduziram uma "mentalidade letrada" nesse grupo. Foi preciso, gradualmente, transformar o modo como a escrita era vista naquele grupo social para caminhar rumo a uma comunidade letrada, rompendo com certos costumes vinculados à teologia cristã como, por exemplo, a datação das cartas comerciais. A esse processo de imposição do letramento de um grupo cultural externo sobre o outro, Street nomeia "Letramento colonial". Paralelo a esse movimento, ele identifica também práticas em que há um "letramento dominante", ou seja, situações em que o letramento não é imposto de um grupo externo em relação à dada comunidade, mas naquelas em que um grupo social dominante dentro de dada cultura apresenta seu modelo de letramento como o mais adequado e se propõe a "ensiná-lo" aos membros de outros grupos sociais dentro da mesma cultura. Isso ocorreu, na visão de Street, nas campanhas de alfabetização conduzidas durante o regime do xá no Irã, durante os anos 1960 e 1970. Nelas, o modelo de letramento urbano amplamente ensinado nas escolas impactava na vida dos homens e mulheres das comunidades rurais e dos/as professores/as. Porém, os/as camponeses/as alvos dessas campanhas de alfabetização já viviam práticas letradas nas escolas vinculadas ao Islã (maktab). Com isso, aqueles/as que conseguiam vincular as práticas ensinadas nas campanhas promovidas por grupos culturais vinculados ao xá com as práticas aprendidas na maktab, conseguiam adaptar esses dois modos de letramento às novas exigências do País a partir de 1970. Os exemplos da Inglaterra Medieval e do Irã servem para pensarmos que os grupos culturais em que pretensamente está sendo introduzido o letramento vivem variadas práticas letradas que não podem "ser simplesmente acomodados em um modelo único, 'autônomo"” de letramento (p. 60). Cabe, portanto, às políticas, programas e campanhas que visam à promoção do letramento, desvincular-se da noção autônoma de letramento e incorporar a noção ideológica do mesmo em suas práticas.

Os conceitos de letramento autônomo, letramento ideológico, letramento colonial e letramento dominante podem ser úteis às pesquisas educacionais brasileiras, particularmente 
aquelas que se debruçam sobre as diferentes políticas de alfabetização/letramento que vem sendo empreendidas em nosso País nos últimos anos. A incorporação dessa noção de letramento nas pesquisas brasileiras pode auxiliar-nos a entender como operam as diferentes políticas públicas de alfabetização, complexificando nosso quadro teórico e ampliando as possibilidades de intervenção no âmbito educacional. Com base nesses conceitos, cabe questionar que "tipo" de letramento vem subsidiando tais políticas, bem como que impactos elas podem ter sobre os grupos culturais para os quais vem sendo indicadas. Afinal, se Street afirma que “o modelo 'autônomo' é dominante na UNESCO” (p. 44), uma rápida avaliação de certas políticas - como a promovida pelo Pacto Nacional Pela Alfabetização na Idade Certa ou no Pró-letramento - parece indicar que as políticas brasileiras vão na mesma direção.

Se na primeira sessão do livro o foco central é no desenvolvimento de políticas de letramento, na segunda, o autor centra-se na discussão sobre "A etnografia do letramento". Dando continuidade ao argumento central do livro relativo às implicações do letramento autônomo e do letramento ideológico, Street defende que a etnografia sozinha não é uma solução mágica para pesquisar letramentos, já que, muitas vezes, ela pode reproduzir os preconceitos do/a pesquisador/a sobre grupos "letrados" e "não-letrados". No capítulo intitulado "Oralidade e letramento como construtos ideológicos", o autor mostra como estudos antropológicos que, de modo geral, tendem a ser relativistas no que concerne às instituições e práticas diversas, acabam caindo no modelo autônomo de letramento e considerando que os grupos que pesquisam são menos lógicos que os ocidentais, em função de sua falta de letramento. Questionando a noção de "culto à carga" - segundo a qual os/as antropólogos/as consideram que as populações nativas acreditam que, por meio de alguns atos ritualizados que incluem práticas letradas, será possível obter a mesma riqueza material dos colonizadores - o autor mostra como muitas das características dos letramentos narradas nas etnografias como ilógicas também estão presentes nas práticas letradas ocidentais e no modo como o letramento é ensinado para as populações nativas. É o caso, por exemplo, da relação entre forma e conteúdo, da manipulação que envolve o letramento e da ambiguidade dos textos, aspectos presentes tanto nas práticas orais, como nas escritas. Para evitar o etnocentrismo nas etnografias que pretendem analisar letramentos em uma perspectiva transcultural, Street propõe que seja construído um quadro teórico e metodológico para o estudo do letramento e da oralidade. 
De certo modo, é isso que o autor faz no capítulo "O uso do letramento e da antropologia no Irã", no qual são buscadas as bases para uma etnografia do letramento que não se apoie no conceito de letramento autônomo. Com base nos Estudos Culturais Contemporâneos - desenvolvidos na Universidade de Birmingham, nos anos 1960 - Street apresenta com detalhes a pesquisa desenvolvida no Irã e que fora apresentada brevemente no segundo capítulo. Utilizando o conceito de cultura como modos de vida permeados pelo poder e pela ideologia, mostram-se as implicações que os diferentes letramentos têm e como a aquisição do letramento "não provoca necessariamente um corte radical com as formas anteriores, locais, de tradição religiosa" (p. 83). Afinal, ideologia para ele é "o lugar de tensão entre autoridade e poder, de um lado, e resistência e criatividade individual, do outro" (p. 173). A entrada de certas práticas de letramento em dada cultura causa, portanto, disputas, adaptações, ajustes e embates entre modelos diversos de letramento. $\mathrm{O}$ diálogo que o autor estabelece com os estudos culturais também pode ser muito produtivo para as pesquisas em educação, sobretudo se considerarmos que já há certa tradição no Brasil com relação a esse campo de estudos (PARAÍSO, 2004), embora poucas pesquisas sobre alfabetização e letramento tenham sido desenvolvidas tendo como base esse referencial teórico. Além disso, outros conceitos que têm sido apropriados pelos estudos culturais pós anos 1990, como representação, discurso e poder, podem ser úteis para a realização de pesquisas que procuram analisar as implicações das diferentes práticas de letramento, particularmente aquelas realizadas em contextos escolares.

Os letramentos escolares constituem a terceira sessão do livro que procura utilizar as ferramentas metodológicas e conceituais elaboradas nos capítulos anteriores em estudos de caso na educação. O primeiro estudo de caso foca nas relações entre famílias de classe média norte-americanas e escola no que tange aos letramentos. Procurando investigar o que fez com que, a despeito da multiplicidade de letramentos existentes na cultura, um deles fosse eleito como o mais adequado, Brian Street (em parceria com Joanna Street) constrói a hipótese de que um dos mecanismos para que isso ocorra é a "pedagogização do letramento". A pedagogia é vista como uma "força ideológica que controla as relações sociais em geral e, em particular, as concepções de leitura e escrita” (p. 122). Em função disso, práticas letradas que não se vinculam ao modelo escolar acabam sendo consideradas inferiores ou inexistentes. No caso investigado, foi possível perceber um forte vínculo entre as práticas desenvolvidas na escola (como a objetificação da língua, o privilégio da língua escrita sobre a oral, a ênfase na 
terminologia gramatical) e a construção de determinado tipo de cidadão, que se aproximava do modelo de classe média. Aliado a isso, o modo como a escola trabalhava com as práticas letradas ajudava a manter a ideia de que o letramento praticado pela escola era neutro ideologicamente, quando o que ele fazia era justamente ajudar a disseminar certa ideologia de classe. Conclui-se também que não havia uma transmissão direta de práticas letradas da escola para a casa, mas um intrincado processo de troca em que ambas as instituições se uniam para atingir o mesmo objetivo de formação do cidadão letrado de classe média, capaz de manter os mesmos bens culturais e econômicos de suas famílias.

No capítulo subsequente, são apresentadas "Implicações dos novos estudos do letramento para a pedagogia". Para isso, dois conceitos operacionais são apresentados: eventos de letramento e práticas de letramento. O primeiro deles refere-se aos momentos que, em dada cultura, a escrita é necessária, sem prescindir, porém, da articulação com as práticas orais. Já práticas de letramento referem-se aos modelos culturalmente construídos em torno dos eventos de letramento. A noção de práticas de letramento mostra as imbricadas relações sociais que permeiam os múltiplos letramentos, fazendo com que eles se insiram em práticas ideológicas. Por meio desse conceito, Street retoma a noção de letramento autônomo, mostrando como as práticas escolares (até mesmo as mais libertárias, como o método Paulo Freire) operam com uma noção que vincula o letramento à superação das desigualdades de classe, o que é, na visão do autor um equívoco. No lugar dessa concepção autônoma, ele propõe uma abordagem que veja o letramento como prática social crítica, que teria como objetivo tornar explícitas as relações de poder que dão base a certos modelos de letramento. Talvez nessa concepção crítica resida a maior contribuição dos novos estudos do letramento para a prática cotidiana nas salas de aula.

Dando continuidade aos estudos críticos, a sessão seguinte pretende elaborar um "quadro teórico crítico", em que se questionem as teorias sobre as quais o senso comum sobre letramento está assentado. A primeira teoria a ser desconstruída é aquela que defende uma "grande divisão entre escrita e oralidade", proposta por Ong. Para esse autor, o letramento permite "uma mudança de uma mentalidade 'pré-lógica' para uma mentalidade 'lógica"” (p. 165), o que levaria as culturas letradas a produzirem a história, a ciência, o pensamento crítico e a abstração. Fortemente marcada por um viés etnocêntrico - já que Ong considera sua própria cultura acadêmica e letrada como modelo ideal de desenvolvimento humano - tal teoria é equivocada, ainda, por conceber que somente a escrita é capaz de fixar o som e a 
experiência. Street se contrapõe a tal noção, mostrando como a língua oral também tem essa capacidade. A problematização que o autor faz também pode contribuir para diferentes pesquisas, particularmente para aquelas que pretendem investigar - por meio da etnografia grupos culturais brasileiros que não utilizam a língua escrita como meio privilegiado de comunicação.

Na mesma direção, no capítulo posterior, são mostrados mitos sobre o letramento que advêm de algumas correntes do pensamento que pretendiam romper com a grande divisão entre oralidade e escrita, mas que continuavam com os mesmos pressupostos teóricos. Um desses mitos é aquele segundo o qual o discurso escrito usa a lexicalização e a gramática para codificar os sentidos, enquanto a língua oral usa aspectos paralinguísticos para obter esses sentidos. Street mostra como essa ideia mantém a divisão entre oralidade e letramento, enquanto, na realidade, tanto uma como o outro utilizam aspectos gramaticais e paralinguísticos para conseguir determinados efeitos de sentido. A ideia de que o discurso oral seria menos coeso do que o escrito também é problematizada pelo autor, assim como a noção de que a língua escrita seria mais direta, enquanto a língua oral seria mais vinculada às pressões sociais da interação face a face. Street mostra, com inúmeros exemplos cotidianos e retirados de pesquisas etnográficas, como esses mitos pretendem manter a hegemonia da concepção ocidental e acadêmica de letramento.

Finalizando o livro, são apresentadas algumas pesquisas que problematizam e complexificam as relações entre políticas, teoria e pesquisa sobre letramento. Trazendo estudos mais recentes, Street recupera algo feito no primeiro capítulo do livro e, dessa vez, problematiza a concepção de letramento subjacente ao PISA ( Programme for International Student Assessmen), mostrando como no âmbito desse programa também se opera com a noção autônoma de letramento. Porém, ampliando a análise realizada no capítulo 1, ele mostra outras políticas (como o LETTER) que procuram trabalhar com uma concepção mais local de letramento, possibilitando a crítica social do mesmo. Além disso, ele apresenta pesquisas que, nos últimos anos, vem trabalhando com a noção de letramento como prática social e, em diferentes países da África e da América Latina, apresentam modos diversos de pensar o letramento. Destaque-se o breve levantamento de pesquisas brasileiras apresentado pelo autor que mostra como, apesar da dificuldade conceitual apontada por Soares (2010), as pesquisas sobre letramento têm se desenvolvido no Brasil e podem ser ainda mais potencializadas com a análise crítica e reflexiva de obras teóricas como a de Brian Street. 


\section{Referências}

SOARES, M. Práticas de letramento e implicações para a pesquisa e para políticas de alfabetização e letramento. In: MARINHO, M. CARVALHO, G. Cultura escrita e letramento. Belo Horizonte: Editora da UFMG, 2010.

PARAÍSO, M. Currículo e as contribuições dos Estudos Culturais. Presença Pedagógica. Belo Horizonte, v. 10, n. 55, jan/fev, 2004.

Recebido em: 23/05/2015

Aprovado para publicação em: 05/10/2016

Publicado em: 27/04/2017 